\title{
Ontogenetic vertebral growth patterns in the basking shark Cetorhinus maximus
}

\author{
Lisa J. Natanson ${ }^{1, *}$, Sabine P. Wintner ${ }^{2}$, Friederike Johansson ${ }^{3}$, Andrew Piercy ${ }^{4}$, \\ Patrick Campbell ${ }^{5}$, Alessandro De Maddalena ${ }^{6}$, Simon J. B. Gulak ${ }^{7}$, Brett Human ${ }^{8}$, \\ Franco Cigala Fulgosi ${ }^{9}$, David A. Ebert ${ }^{10}$, Farid Hemida ${ }^{11}$, Frederik H. Mollen ${ }^{12}$, \\ Stefano Vanni ${ }^{13}$, George H. Burgess ${ }^{4}$, Leonard J. V. Compagno ${ }^{14}$, \\ Andrew Wedderburn-Maxwell ${ }^{15}$
}

\footnotetext{
${ }^{1}$ National Marine Fisheries Service (NMFS), Northeast Fisheries Science Center, NOAA, 28 Tarzwell Drive, Narragansett, Rhode Island 02882-1199, USA

${ }^{2}$ Natal Sharks Board, Private Bag 2, 4320 Umhlanga Rocks, and Biomedical Resource Unit, University of KwaZulu-Natal, PO Box X54001, Durban 4000, South Africa

${ }^{3}$ Vertebrate Section, Göteborg Natural History Museum, Box 7283, 40235 Göteborg, Sweden

${ }^{4}$ Florida Program for Shark Research, Florida Museum of Natural History, University of Florida, PO Box 117800, Gainesville, Florida 32611, USA

${ }^{5}$ Department of Zoology, Natural History Museum, Cromwell Road, London SW7 5BD, UK

${ }^{6}$ Banca Dati Italiana Squalo Bianco, Via L. Ariosto 4, 20145 Milan, Italy

${ }^{7}$ Pelagic Observer Program, South East Fisheries Science Centre, National Marine Fisheries Service, NOAA, 75 Virginia Beach Drive, Miami 33149, Florida, USA

${ }^{8}$ Marine Science and Fisheries Centre (Biodiversity Project), PO Box 467, PC 100 Muscat, Sultanate of Oman

${ }^{9}$ Dipartimento Scienze della Terra, Università di Parma, Parco Area delle Scienze 152/A, 43100 Parma, Italy

${ }^{10}$ Pacific Shark Research Center, Moss Landing Marine Laboratories, 8272 Moss Landing Road, Moss Landing, California 95039, USA

${ }^{11}$ Laboratoire Ecologie et Environnement (Projet Halieutique), Faculté des Sciences Biologiques (FSB), Université des Sciences et Techniques Houari Boumedienne (USTHB), BP 32, El Alia, 16111 Bab Ezzouar, Alger, Algeria

${ }^{12}$ Elasmobranch Research, Meistraat 16, 2590 Berlaar, Belgium

${ }^{13}$ Sezione di Zoologia ‘La Specola', Museo di Storia Naturale dell'Università, Via Romana 17, 50125 Florence, Italy

${ }^{14}$ Shark Research Center, South African Museum, PO Box 61, 8000 Cape Town, South Africa

${ }^{15}$ Umhlanga Radiology, Radiology Department, Umhlanga Hospital, Private Bag X09, 4320 Umhlanga Rocks, South Africa
}

\begin{abstract}
Age and growth of the basking shark Cetorhinus maximus (Gunnerus) was examined using vertebral samples from 13 females (261 to $856 \mathrm{~cm}$ total length [TL]), 16 males (311 to $840 \mathrm{~cm}$ TL) and 11 specimens of unknown sex (376 to $853 \mathrm{~cm} \mathrm{TL).} \mathrm{Vertebral} \mathrm{samples} \mathrm{were} \mathrm{obtained} \mathrm{worldwide}$ from museums and institutional and private collections. Examination of multiple vertebrae from along the vertebral column of 10 specimens indicated that vertebral morphology and band pair (alternating opaque and translucent bands) counts changed dramatically along an individual column. Smaller sharks had similar band pair counts along the length of the vertebral column while large sharks had a difference of up to 24 band pairs between the highest and lowest count along the column. Our evidence indicates that band pair deposition may be related to growth and not time in this species and thus the basking shark cannot be directly aged using vertebral band pair counts.
\end{abstract}

KEY WORDS: Basking shark $\cdot$ Cetorhinus maximus $\cdot$ Age $\cdot$ Growth $\cdot$ Vertebrae 


\section{INTRODUCTION}

The basking shark Cetorhinus maximus (Gunnerus) has been the target of various fisheries worldwide as far back as the 18th century (Castro et al. 1999). Performance of historical basking shark fisheries suggests that the species is particularly susceptible to overfishing (Castro et al. 1999). The basking shark is assessed as 'Vulnerable' on the International Union for the Conservation of Nature and Natural Resources (IUCN) Red List of Threatened Species and is listed in Appendix II of the Convention on International Trade in Endangered Species of Wild Fauna and Flora (CITES) (http://sea. unep-wcmc.org. Little is known about the biology of this species, including age and growth (Castro et al. 1999).

The age of a shark is commonly determined by counting alternating opaque and translucent band pairs deposited in vertebrae. Access to basking shark vertebrae, however, is very limited, especially those for which accurate morphological information is available. This has hampered attempts to elucidate age and growth in this species and previous results have been questioned (Parker \& Stott 1965, Pauly 2002).

Previous studies of basking shark age have relied on small sample sizes and suspect methodology. Matthews (1950) presented a growth curve based on length frequency information from 13 individuals, but stressed that it was a tentative growth curve. Parker \& Boeseman (1954) reanalyzed Matthews' (1950) data with an additional 41 data points obtained from the literature and museums. Parker \& Stott (1965) re-examined the Parker \& Boeseman (1954) data using a graphical approach and an empirical growth formula, added data, and attempted verification with vertebral counts from 5 specimens. Using all the graphical analyses and vertebral band pair counts, Parker \& Stott (1965) concluded that there were 7 pre-birth band pairs and that subsequent band pairs were deposited biannually. These 3 papers contained data adjustments (adding lengths to the original data points), questionable assumptions (arbitrary monthly grouping of animals), or plotting and/or calculation errors. Pauly (1978) questioned the biannual deposition theory, reanalyzed all the previous data using several growth models and concluded that the previous analyses were erroneous and the 7 pre-birth bands 'bizarre'.

While these studies used the best data available at the time, the sample sizes were quite limiting. We attempted to determine age for Cetorhinus maximus based on vertebral band pair counts from sources worldwide.

\section{MATERIALS AND METHODS}

Sampling. Vertebral samples from 40 basking sharks were obtained from museums and institutional and pri- vate collections. Samples came from several oceans and seas, including the North Atlantic, South Atlantic, Mediterranean, Adriatic, Southwest Indian, North Sea and Northeast Pacific. Vertebrae were preserved using methods of the collectors or institutions, and included: ethanol and/or formaldehyde fixation, drying, and freezing. Samples ranged from 1 vertebra to the entire vertebral columns from each specimen. Maturity condition of individual samples was based on the data provided by the collector (see Table 1).

Morphological measurements were inconsistent. In many cases it is unknown if the measurement was taken over the body or was a straight line (caliper) measurement; additionally, length type was not always specified. Often the location of the vertebrae along the column was not specified.

Total length (TL, cm) with the tail in natural position was used throughout this study. In specimens where the type of length was not given, the measurement or estimate was assumed to be TL. A variety of morphological measurements was available for these specimens, including fork and pre-caudal lengths (FL and PCL, respectively) and girth from behind the pectoral, dorsal and pelvic fins. These data and data from the literature (Bigelow \& Schroeder 1948, Matthews 1950, Wood 1957, Siccardi 1961, Chen 1963, Springer \& Gilbert 1976, Cadenat \& Blache 1981, Izawa \& Shibata 1993, Soldo 1999) were used to calculate the following conversions:

$$
\begin{gathered}
\mathrm{TL}=1.09 \times \mathrm{FL}+12.01 \\
\left(\mathrm{r}^{2}=0.996, \mathrm{n}=16 ; 261 \text { to } 846 \mathrm{~cm} \mathrm{TL}\right) \\
\mathrm{TL}=1.20 \times \mathrm{PCL}+15.53 \\
\left(\mathrm{r}^{2}=0.995, \mathrm{n}=17 ; 261 \text { to } 855 \mathrm{~cm} \mathrm{TL}\right) \\
\mathrm{FL}=1.14 \times \mathrm{PCL}-8.32 \\
\left(\mathrm{r}^{2}=0.999, \mathrm{n}=20 ; 261 \text { to } 846 \mathrm{~cm} \mathrm{TL}\right)
\end{gathered}
$$

Calculated TL values are indicated throughout with ${ }^{\mathrm{a}}$.

The TL-weight (WT, kg) relationship was generated using data from the collected specimens and published data (Bigelow \& Schroeder 1948, Wood 1957, Siccardi 1961, Springer \& Gilbert 1976, Cadenat \& Blache 1981, Howes 1998, Soldo 1999, Serena et al. 2000, Zuffa et al. 2001, Schwartz 2002) and references contained therein;

$$
\begin{gathered}
\mathrm{WT}=9.0073 \times 10^{-6} \times \mathrm{TL}^{2.94} \\
(\mathrm{n}=59, \text { range } 249 \text { to } 1000 \mathrm{~cm}, 95 \% \mathrm{CI} \text { on exponent }= \\
\left.2.74 \text { to } 3.12, \mathrm{r}^{2}=0.944\right)
\end{gathered}
$$

Vertebral measurements were made by the collection institutions using guidelines for whale sharks following Wintner (2000). Measurements included length, dorsal and lateral diameter of each centrum, as well as diameter at the angle change (Wintner 2000). The angle change on the centrum face was regarded as the birthmark (Wintner 2000). Analyses were per- 
formed separately on vertebrae obtained from 3 different regions: trunk, abdomen and tail. All vertebral dimensions (VD, cm) were related to TL to determine the proportional relationship between somatic and vertebral growth so that the correct back-calculation method could be chosen (Goldman 2004).

The relationship between lateral diameter (LD, cm) and TL was calculated to determine the best method for back-calculation of length-at-age data and to confirm the interpretation of the birth band. Regressions were fitted to the data by sex and an analysis of covariance (ANCOVA) was used to test for difference between the sexes. Based on recommendations in Cailliet \& Goldman (2004), multiple back-calculation methods were examined to find the most appropriate biological and statistical fit.

The analyses included the quadratic-modified DahlLea back-calculation method:

$$
\mathrm{TL}_{i}=\mathrm{TL}_{\mathrm{c}} \times\left[\left(a+b \mathrm{LD}_{i}+c \mathrm{LD}_{i}^{2}\right) /\left(a+b \mathrm{LD}_{\mathrm{c}}+c \mathrm{LD}_{\mathrm{c}}^{2}\right)\right]
$$

where $a, b$ and $c$ are the quadratic fit parameter estimates, $\mathrm{LD}_{i}$ are the lateral diameters at band $i$ and $\mathrm{LD}_{\mathrm{C}}$ is the lateral diameter at capture; as well as the linearmodified Dahl-Lea method:

$$
\mathrm{TL}_{i}=\mathrm{TL}_{\mathrm{c}} \times\left[\left(a+b \mathrm{LD}_{i}\right) /\left(a+b \mathrm{LD}_{\mathrm{c}}\right)\right]
$$

where $a$ and $b$ are the linear fit parameter estimates. A minimum of 1 vertebra and, if available, multiple vertebrae, from different parts of the vertebral column was removed for processing. Every fifth vertebra from whole columns of 3 specimens was analyzed for changes in morphology, size and band pair count. $\mathrm{X}$-radiography and sectioning were used to enhance the visibility of band pairs.

X-radiography. X-radiographic settings varied between the laboratories due to different machines, film and vertebral sizes. The diameter at the angle change was marked on each image. Band pairs were counted and measured twice by 1 reader (results hereinafter referred to as X-radiography). Images were scanned into the computer using a CreoScitex EverSmart Jazz ${ }^{1}$ scanner with EverSmart Jazz Scanning Software version 3. Band pairs (consisting of 1 opaque and 1 translucent band) were then counted and measured by 1 reader using digital image analysis software Image Pro ${ }^{\circledR}$ Discovery (hereinafter referred to as digital image analysis). X-radiographs were produced for each vertebra along the column of Specimen 36.

Sectioning. Sectioning was only performed on vertebrae from the western North Atlantic (Specimens 7 to 17,37 to 40 ). One vertebra from each animal and every

1Reference to trade names does not imply endorsement by the National Marine Fisheries Service fifth vertebra from 2 whole columns were processed. The vertebrae were sectioned using either a Diamond Pacific Model TC-6 trim saw with a diamond blade or a standard hacksaw. Each centrum was sectioned through the center at the point where the lateral diameter measurement was taken. The resulting bow-tie sections were directly photographed with a millimeter scale using a Nikon Coolpix 5700 camera system or with an MTI CCD 72 video camera attached to an SZX9 Olympus stereomicroscope using reflected light. Sections were preserved in $70 \%$ ethanol. Band pairs were counted and measured on the images using Image Pro 4 software. Measurements on the sections were made along the same plane as would have been measured on the vertebral face so that comparisons could be made for both the angle change (birth band) and lateral diameter.

Bias. Aging bias and precision were analyzed by looking at percent agreement ( \pm 1 band pair) and contingency tables. Chi-squared tests of symmetry (McNemar 1947, Bowker 1948, Hoenig et al. 1995, Evans \& Hoenig 1998) were performed to determine whether differences between readers were biased or due to random error (Cailliet \& Goldman 2004). Additionally, bias graphs and coefficient of variation (CV) were examined (Chang 1982, Campana et al. 1995).

\section{RESULTS}

Vertebrae were obtained from 40 specimens: 13 females (261 to $\left.856^{\mathrm{a}} \mathrm{cm}\right), 16$ males $(311$ to $840 \mathrm{~cm}$ ) and 11 specimens of unknown sex (376 to $853 \mathrm{~cm})$ (Table 1). Vertebrae from 37 basking sharks (261 to $856^{\mathrm{a}} \mathrm{cm}$ ) were X-rayed, and X-radiographs were scanned for digital image analysis. Vertebrae from 12 of the 37 were also sectioned. Vertebrae from 3 other sharks were processed exclusively with sectioning. Nineteen specimens either lacked morphological measurements or were from either the extreme cranial or the tail area, and so could not be used for age-related analyses. The 21 samples used for agerelated analyses consisted of 9 females (261 to $716 \mathrm{~cm}$ ), 11 males (311 to $840 \mathrm{~cm}$ ) and 1 specimen of unknown sex $(480 \mathrm{~cm}$; Table 1). Band counts from all specimens were examined for comparison between processing techniques and the differences in band counts along the vertebral column.

\section{Morphology of the vertebrae}

Basking shark vertebrae are generally round but vary slightly in shape and morphology depending on their location along the vertebral column. The position 


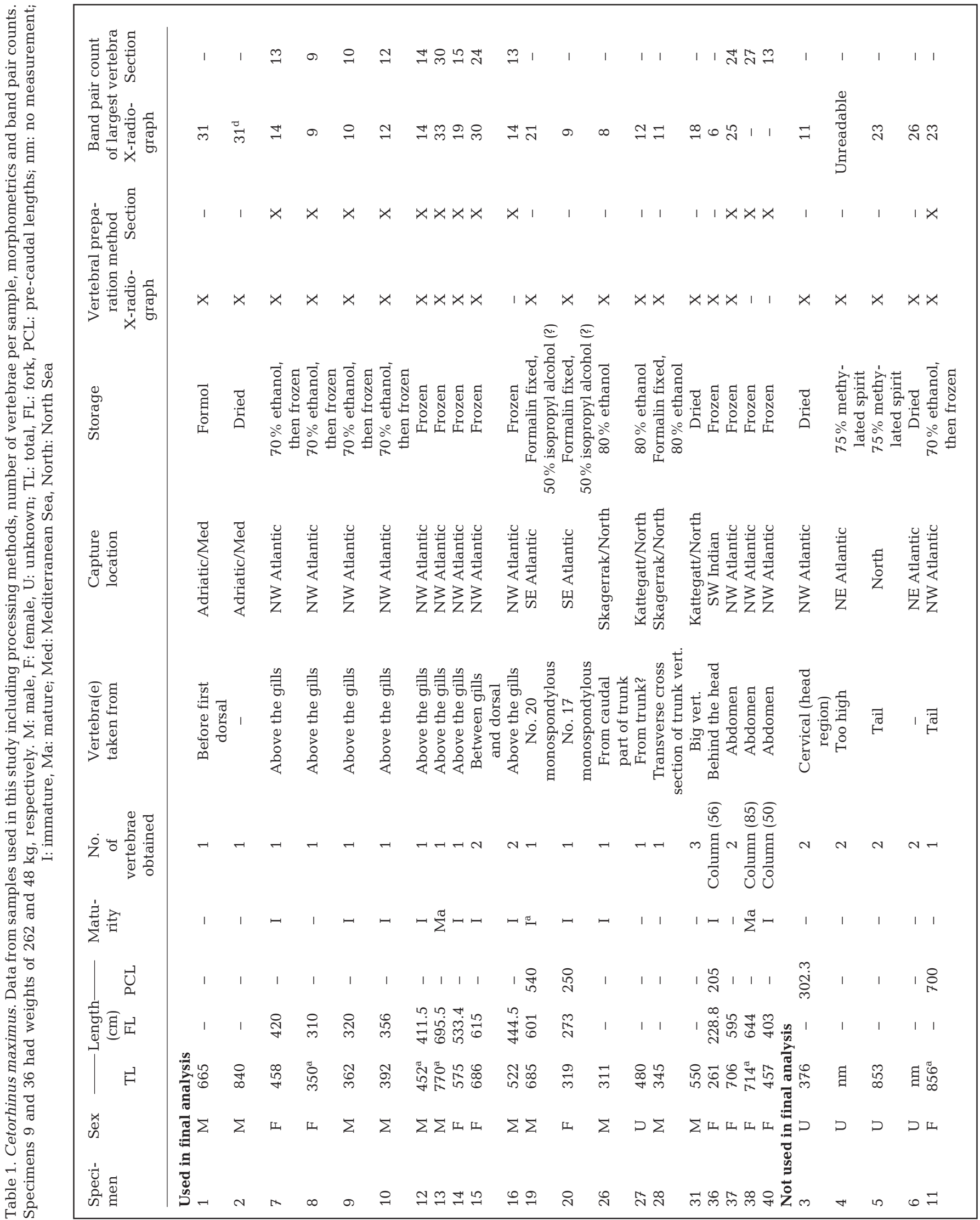




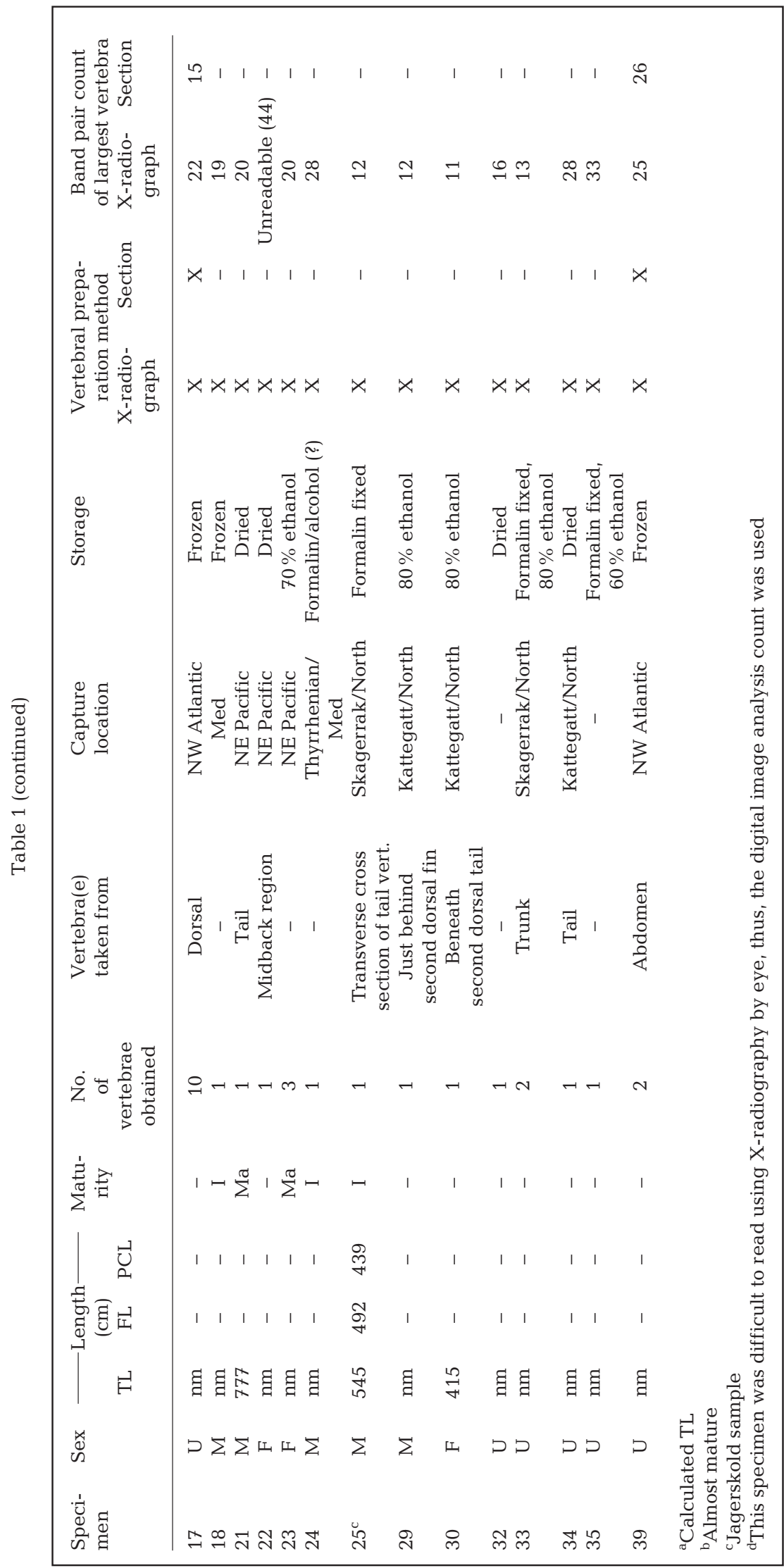

of the basopophyses (following the terminology of Walker 1975) provides only a coarse indication of the origin of each vertebra (Fig. 1). Cranial vertebrae (Nos. 1 to $\sim 10$ ) can be distinguished by basopophyses that are directed ventrolaterally. Abdominal vertebrae (Nos. $~ 10$ to $\sim 30$ ) are generally the largest and the basopophyses are directed laterally. In trunk vertebrae (Nos. $\sim 30$ to $\sim 55$ ), the basopophyses start to come together ventrally, while in tail vertebrae (Nos. $\sim 55$ to tail tip), they combine to form the hemal arch (Fig. 1). Vertebrae from all regions of the body contain distinct, evenly spaced band pairs. Unless otherwise noted, the following analyses use only samples obtained from above the gill area $(\mathrm{n}=21)$.

Each of the 3 vertebral measurements showed significant positive relationships to TL (Fig. 2). The shape of the vertebrae change as the shark grows, with the vertebrae often becoming wider at the ventral surface. It is due to this shape change that we used multiple VD measurements. Though we compared all the VD measurements that we made to TL, we used the LD measurement for the back-calculation as the lateral growth is symmetrical. The relationship between LD and TL was slightly curvilinear. A linear regression gave a significant fit to the data $\left(\mathrm{TL}=[37.05 \times \mathrm{LD}]+162.70 ; \mathrm{r}^{2}=\right.$ $0.933)$; however, a quadratic equation produced a slightly better fit ( $\mathrm{TL}=49.06$ $\left.+[63.42 \times \mathrm{LD}]+\left[-1.26 \times \mathrm{LD}^{2}\right] ; \mathrm{r}^{2}=0.943\right)$ based on a lower mean square error (1948.35 and 1750.46, respectively) and a $t$-test that showed the third parameter to be significantly different from $0(t=$ 1.77; $\mathrm{df}=21, \mathrm{p}=0.09$ ) An ANCOVA using $\ln$-transformed data was used to compare the LD-TL relationships between the sexes. As there was no significant difference between either the slopes or intercepts $(p=0.30$ and 0.42 , respectively), the data were combined. It was still necessary to compare the mean back-calculated length-at-age from both the linear- and quadraticmodified Dahl-Lea back-calculation equations to determine if the better statistical fit equated to a better biological fit. 


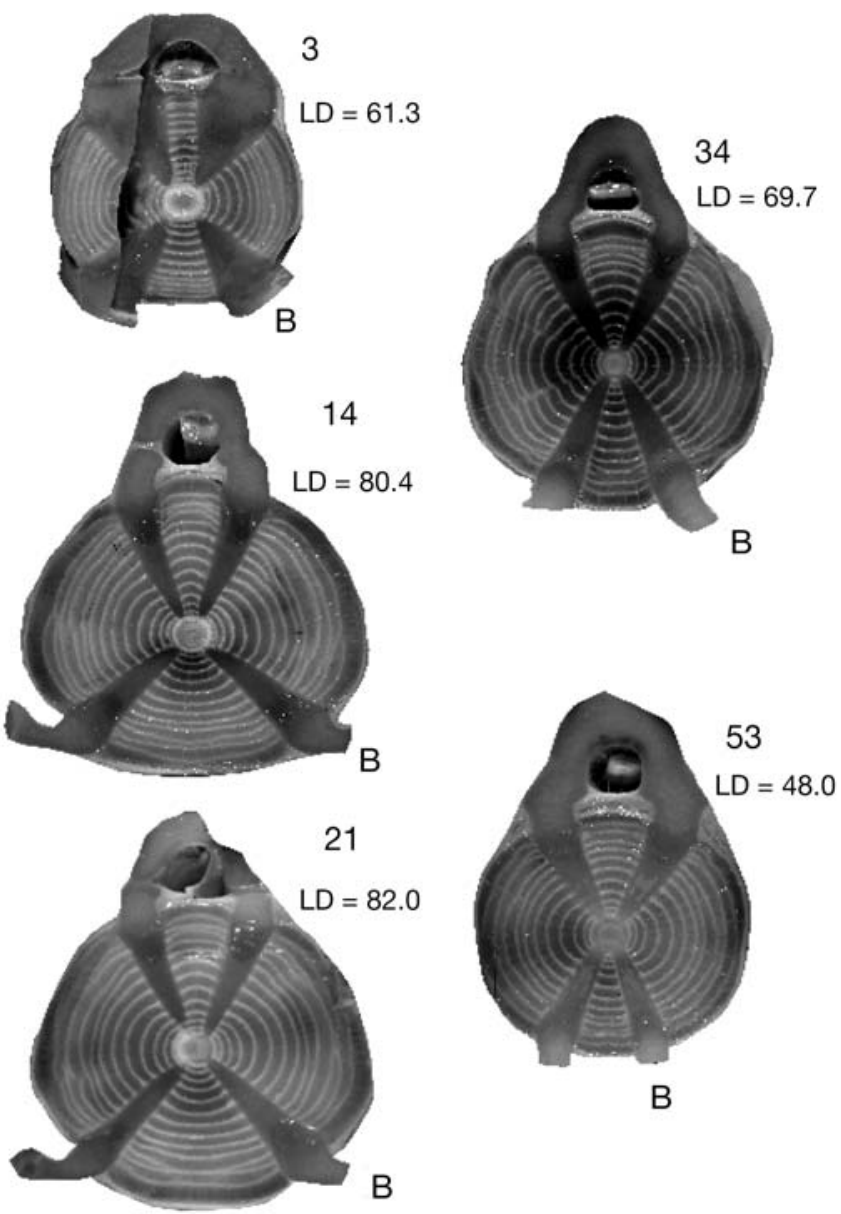

Fig. 1. Cetorhinus maximus. Photographs of 5 vertebrae from the vertebral column of Specimen 40 (total length, TL $=457$ $\mathrm{cm})$. Photographs are not to scale. Lateral diameters (LD, mm) are shown for each vertebra. $\mathrm{B}=$ basapophysis. Terminology follows Walker (1975). Number refers to position of the vertebra along the vertebral column

\section{Whole columns}

Examination of vertebrae from different positions along the column of 3 specimens of various lengths (261, 457 and $714 \mathrm{~cm})$ showed that the vertebral dimensions decline as vertebral number increases (Fig. 3a). This trend is minor in small animals and dramatic in larger animals. Analyses of the VD-TL relationship were performed separately on vertebrae obtained from 3 different regions: abdomen, trunk and tail (as described in 'Results; Morphology of the vertebrae'). Comparison of the regressions of these 3 regions indicated that there was a significant difference in these relationships for all $3 \mathrm{VD}$ measurements and all 3 regions (ANOVA; $\mathrm{p}<0.05$ ); therefore, conversions of VD to TL can only be used if the vertebrae are taken from the same region of the body.

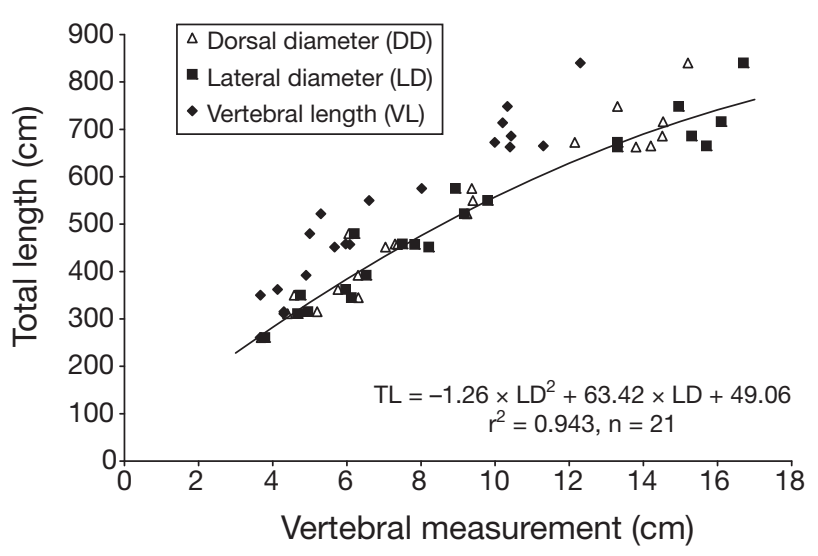

Fig. 2. Cetorhinus maximus. Relationship between vertebral dimensions and total length (TL). Quadratic fit is shown for the lateral diameter relationship
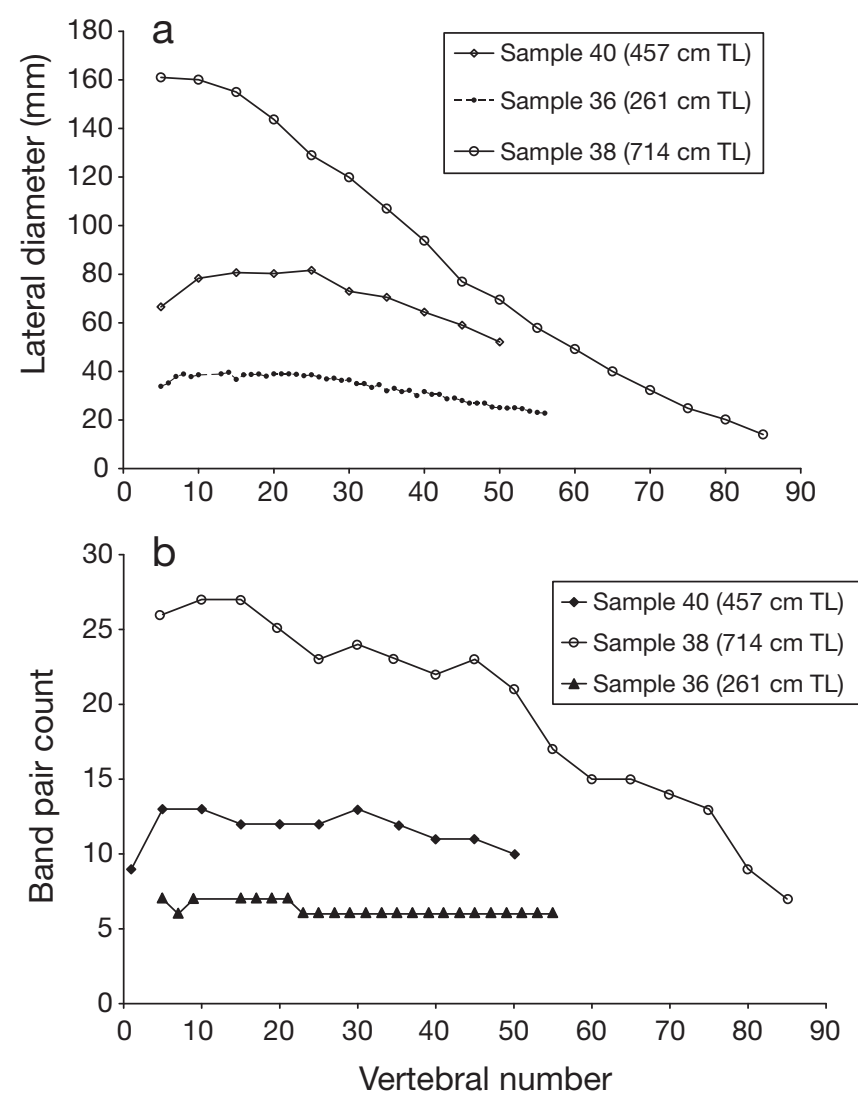

Fig. 3. Cetorhinus maximus. Relationship between (a) lateral diameter or (b) band pair number and vertebral number for 3 specimens. Specimens $36(261 \mathrm{~cm})$ and $40(457 \mathrm{~cm})$ are head to pre-caudal pit, while Specimen $38(714 \mathrm{~cm})$ starts just behind the head (estimated at vertebra no. 5) and extends to the tip of the tail. TL: total length

Band pair counts differed along the vertebral column, particularly in the largest individual. Counts were low at the cranium, increased to a plateau and 
then decreased toward the caudal region (Fig. 3b). Specimen $38(714 \mathrm{~cm})$ was missing the first few vertebrae of the column, thus the extreme cranial vertebral counts are missing. However, it is clear that the counts along this column follow the described pattern, as the first vertebra counted ( No. 5) was lower than the subsequent 2 ( Nos. 10 and 15), followed by a steep decline in band pair count to the caudal region. Band pair count along the column changes ontogenetically. The band pair counts of vertebrae of a small basking shark $(261 \mathrm{~cm})$ (from plateau to pre-caudal pit) never differed by more than 1 . However, counts from the $457 \mathrm{~cm}$ (from plateau to pre-caudal pit) and $714 \mathrm{~cm}$ (from plateau to tip of tail) specimens differed by up to 3 and 20 band pairs, respectively. Additionally, comparisons of counts between cranial and caudal vertebrae from the same specimen of 8 additional sharks showed clear differences in band pair counts in the larger specimens (Table 2).

\section{Angle change}

The diameter of the angle change differed depending on the location of the vertebra along the vertebral column. Due to the subjectivity of the location of the angle change on the face of the vertebrae, the angle change measurement between different researchers was not consistent. The angle change is generally presumed to represent the birth band (Casey et al. 1985) and those bands deposited prior to the angle change pre-birth bands; although we do not have validation, we will use this terminology. Average birth VD and numbers of pre-birth bands were derived from the vertebral sections only.

Using the sections only ( $\mathrm{n}=11$ ), the number of prebirth bands ranged from 6 to 10 (mean $\pm 95 \% \mathrm{CI}=8.4 \pm$ 0.81). The average angle change diameter occurred at

Table 2. Cetorhinus maximus. Data on samples with $>1$ vertebra from an individual vertebral column. Number in parentheses is approximate number along the column, if known. Large, medium and small are relative to available vertebrae from the sample and not to area along the column. TL: total length, na: not available

\begin{tabular}{|ccccc|}
\hline Specimen & TL $(\mathrm{cm})$ & Large & Medium & Small \\
\hline 3 & 375.9 & $10(2)$ & na & $11(35)$ \\
5 & 853.4 & $26(40)$ & na & $20(45)$ \\
15 & 686 & $30(10)$ & na & $22(45)$ \\
31 & 550 & $19(40)$ & $18(50)$ & $8(60)$ \\
4 & na & 27 & na & 15 \\
6 & na & 27 & na & 15 \\
23 & na & 13 & 13 & 13 \\
33 & na & 12 & na & 11 \\
\hline
\end{tabular}

$5.26 \mathrm{~cm}(95 \% \mathrm{CI}, \pm 0.47 \mathrm{~cm})$. Mean length at birth calculated using the quadratic-modified Dahl-Lea backcalculation method ranged from 87 to $321 \mathrm{~cm}$ (mean \pm $95 \% \mathrm{CI}=196.8 \pm 57.2 \mathrm{~cm}$ ), while that calculated using the linear-modified Dahl-Lea back-calculation method ranged from 243 to $376 \mathrm{~cm}$ (mean $\pm 95 \% \mathrm{CI}=301.2 \pm$ $30.9 \mathrm{~cm})$

\section{Bias and precision of band pair counts}

Band pairs were visible in all vertebrae using all techniques (Fig. 4). In some cases, dried vertebrae were distorted and interpretation was difficult. In addition, band pairs at the centrum edges of large vertebrae were difficult to discern using X-radiography. Two vertebrae were considered unreadable using
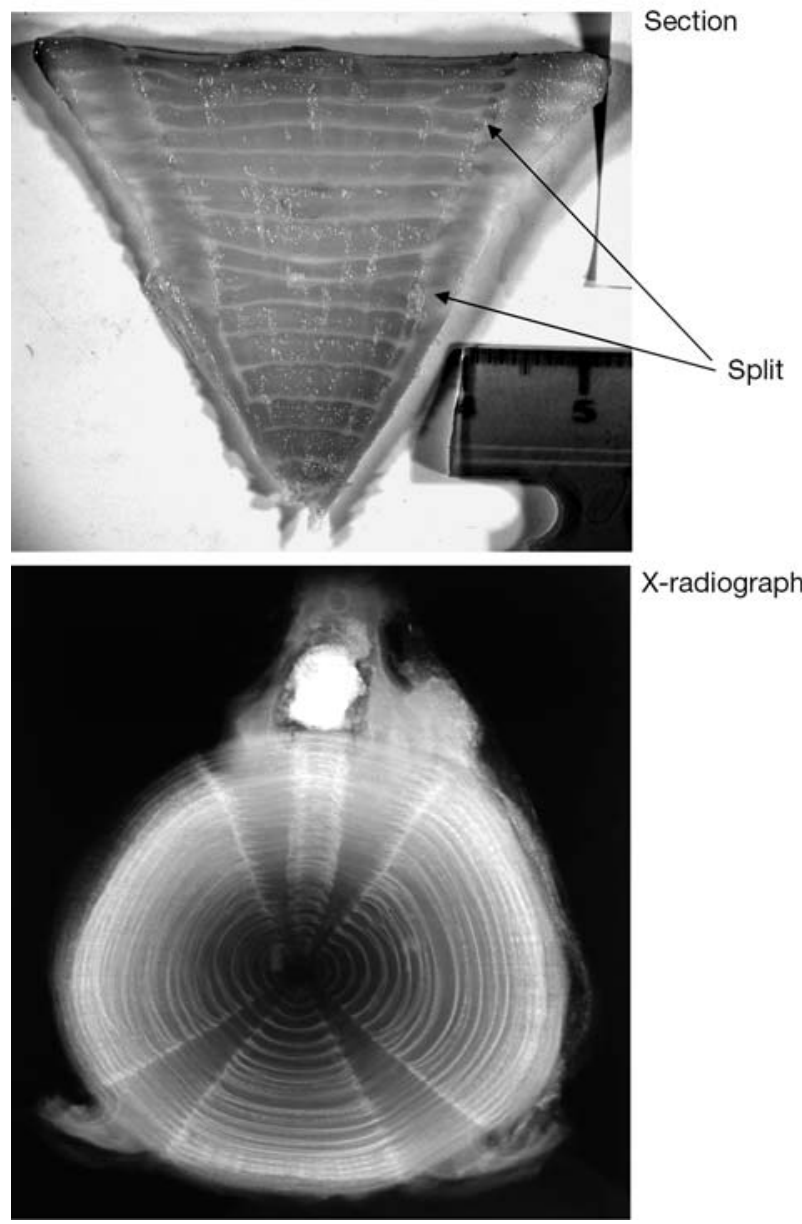

Fig. 4. Cetorhinus maximus. Comparison of X-radiographed and sectioned vertebrae from Specimen 13. A split band is noted on the edge of the sectioned vertebrae; this would show on an X-radiograph as 2 band pairs (see 'Results; Bias and precision of band pair counts') 
X-radiography (Table 1). Sections provided very distinct band pairs on fish of all lengths.

Comparison of repeated counts using X-radiography indicated no systematic bias between counts 1 and 2 of 1 reader (Fig. 5). The individual CVs between counts fluctuated around the mean at 4.0. Percent agreement to within 1 band pair occurred in $80 \%$ of the samples (56 of 70). Additionally, the McNemar (1947), Bowker (1948) and Evans \& Hoenig (1998) chi-squared tests of symmetry gave no indication that differences between counts 1 and 2 were systematic rather than due to random error $\left(\chi^{2}\right.$ test, $\left.p>0.05\right)$. This level of precision was considered acceptable, and the second count was used in the growth curve analyses. Though the precision (repeatability) of the counts was high, the accuracy (reflection of the true age) was not.

Comparison of counts using vertebral sections yielded a slightly lower CV $(2.5 \%)$. While the low sample size limits the value of the analyses, the bias graphs indicated no bias between counts. Percent agreement to within 1 band pair occurred in $83 \%$ of the samples (10 of 12). Additionally, the McNemar (1947), Bowker (1948) and Evans \& Hoenig (1998) chi-squared tests of symmetry gave no indication that differences between counts 1 and 2 were systematic rather than due to random error $\left(\chi^{2}\right.$ test, $\left.p>0.05\right)$. The sectioned counts were then compared to those obtained using digital image analysis and X-radiography.

While good agreement was found between counts obtained by a single method, counts differed depending on the method used. Percent agreement to within 1 band pair between digital image analysis and X-radiography occurred in $50 \%$ of the samples (21 of 42 ). However, $21 \%$ (9) of readings disagreed by 4 or more

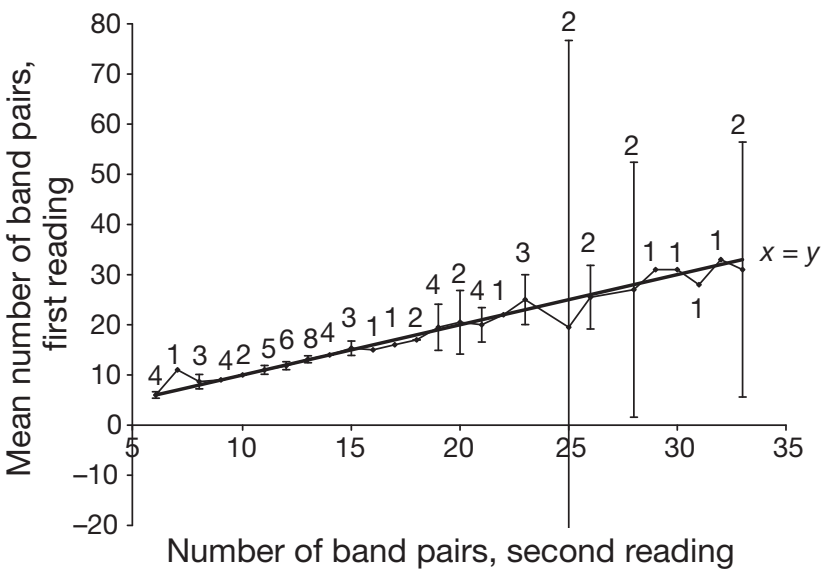

Fig. 5. Cetorhinus maximus. Pairwise comparison of vertebral counts from 2 replicate band counts from X-radiographed specimens. Each error bar represents the 95\% CI for the mean count from Reading 1 related to all fish with a given count in Reading 2. Sample number is presented above each error bar. The 1 to 1 equivalence line is also presented band pairs. The Bowker (1948) and Evans \& Hoenig (1998) chi-squared tests of symmetry gave no indication that differences between these methods were systematic rather than due to random error $\left(\chi^{2}\right.$ test, $\mathrm{p}>$ 0.05). In contrast, the McNemar (1947) test did indicate that there was a systematic error $\left(\chi^{2}\right.$ test, $\left.\mathrm{p}<0.05\right)$. Graphical comparison of these counting methods supported the McNemar (1947) results, as it was apparent that counts from digital image analysis were higher than those obtained from X-radiography alone. The tests of symmetry using sectioning related to digital image analysis $(\mathrm{n}=8)$ gave no indication that differences between these methods were systematic rather than due to random error $\left(\chi^{2}\right.$ test, $\left.\mathrm{p}>0.05\right)$. Percent agreement to within 1 band pair between digital image analysis and sectioning occurred in $50 \%$ of the samples (4 of 8). However, when sectioning was compared to X-radiography $(\mathrm{n}=12)$, the Evans \& Hoenig (1998) result indicated a significant difference $\left(\chi^{2}\right.$ test, $\mathrm{p}<$ 0.05), though the McNemar (1947) and Bowker (1948) tests did not. Percent agreement to within 1 band pair between sectioning and X-radiography occurred in $58 \%$ of the samples ( 7 of 12 ). Both methods that rely on X-radiography produced higher counts than sectioning, based on graphical comparison, though the small sample sizes limit the usefulness of these analyses (Fig. 6).

Sectioning produced high quality images on all sizes of samples. Many splits in the opaque band were evident in sections of large vertebrae. These splits occurred at the edge of the corpus calcareum at what would be the face of the vertebra (Fig. 4). In an X-radiograph of the vertebral face, these splits would appear

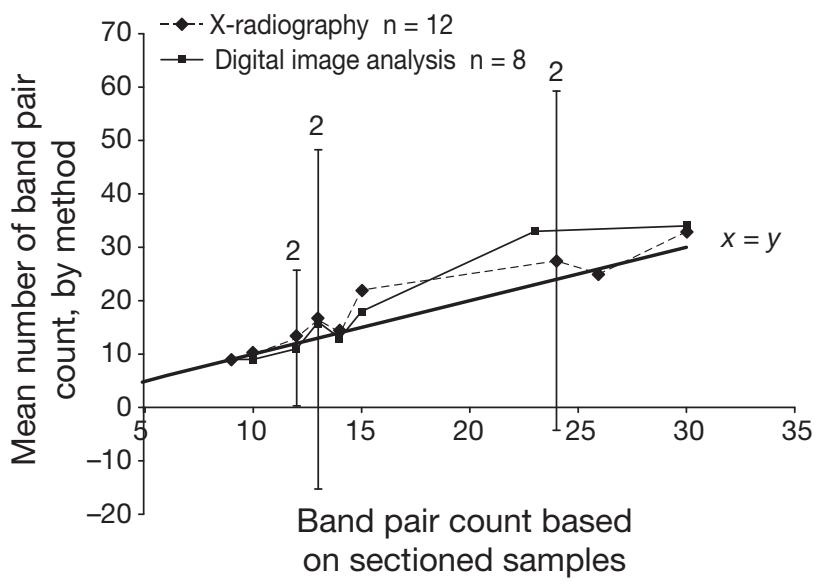

Fig. 6. Cetorhinus maximus. Pairwise comparison of vertebral counts from X-radiography and digital image analysis. Each error bar represents the $95 \%$ CI for the mean count from reads based on X-radiography and digital image analysis to all fish of a given count in the reading based on sections. $\mathrm{n}=1$ except where noted. The 1 to 1 equivalence line is also presented 
as distinct bands and thus lead to over-counting. Additionally, X-radiographs of a whole vertebra penetrate through both faces of the vertebral cone. Thus, shadows of the band pairs on the backside will appear to be on the face that is being counted, which can lead to over-counting. Due to the inability of the software to distinguish between a shadow and a band, the digital image analysis method appeared to consistently overestimate the band pair count. The human reader would also tend to overestimate counts in the larger fish when using X-radiographs due to the difficulty of 'reading' the edges of the large specimens and the splits that would not be distinguished in the X-radiograph. The lower CV from the sectioning method also indicates that this method is more repeatable. Unfortunately, due to the difficulty in obtaining Cetorhinus maximus vertebrae to section, we had to primarily use the $\mathrm{X}$-radiography method in our analyses. Band pair counts for 21 sharks that were used in the final analysis included 11 that were based on sections and 10 based on X-radiographs. Only 4 of the 10 with X-radiographs had band pair counts $>17$. Since this was the point where counts obtained from the 2 processing methods started to diverge (with the X-radiograph counts slightly higher), only the 4 samples with $>17$ band pairs were likely to be affected by processing differences, thus these are highlighted in the figures.

\section{Band pair counts and total length}

For both sexes, the number of band pairs increased with increasing length (Fig. 7a). The maximum number of band pairs for males and females were 30 and 27 (Specimens 13 and 38), respectively, for those where vertebral location in the spinal column was known. The highest number of band pairs in any sample was 33 using X-radiography (Specimens 13 and 35) and 47 from digital image analysis (Specimen 35$)$. The smallest specimen (No. 36) had 6 band pairs.

\section{DISCUSSION}

It is evident upon examination of published literature on basking shark vertebral morphology and age and growth that authors have known that the basking shark vertebrae are irregular compared to other species of elasmobranch. Hasse (1882) and Ridewood (1921) highlighted 2 points about the vertebral centra of the basking shark that are critical: (1) that '...in passing back from the root of the caudal fin the concentric lamellae dwindle...' (Ridewood 1921) and (2) that the basking shark vertebral centra are different from other lamnoids such that the adult hind caudal vertebra are

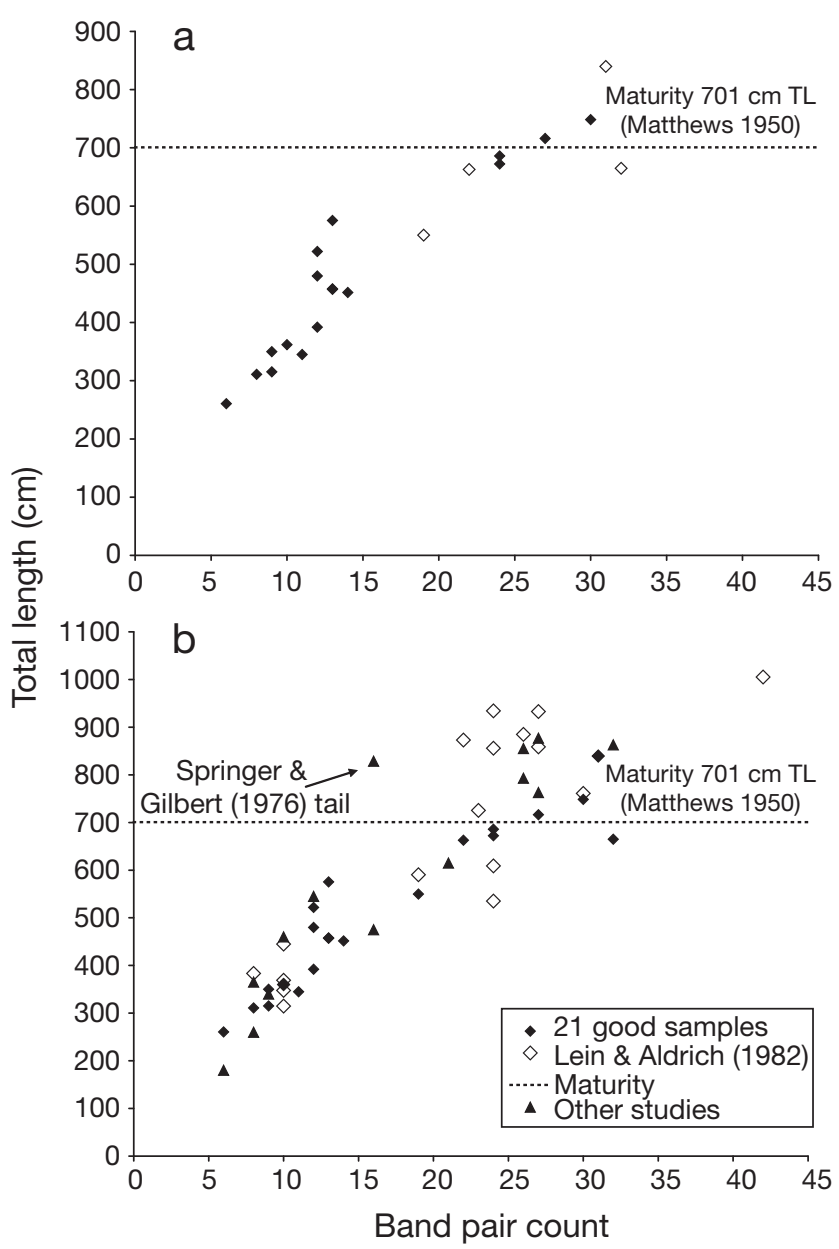

Fig. 7. Cetorhinus maximus. (a) Growth data based on vertebral band counts from 21 specimens. Open diamonds are samples processed using X-radiography and having counts $>17$. (b) Growth data including samples from the literature and this analysis

more recognizable as lamnoid in character than the trunk and anterior caudal vertebrae of the young. Ridewood (1921) also noted that the band pair counts change along the vertebral column. The difference in appearance of basking shark vertebrae from the white shark Carcharodon carcharias, shortfin mako Isurus oxyrinchus, salmon shark Lamna ditropis, porbeagle Lamna nasus or thresher Alopias vulpinus is clear and verifies the differences Hasse (1882) and Ridewood (1921) mentioned. Additionally, in the porbeagle, shortfin mako and thresher, all vertebrae along the column have the same number of band pairs (Natanson et al. 2002, 2006, B. Gervelis [NMFS] unpubl. data). Even while proposing the biannual band pair deposition hypothesis, Parker \& Stott (1965) cast doubt on it for the same reasoning we provide: 'the irregularities that occur in a single vertebra, the reduced number of rings 
in the caudal region and the apparent existence of seven rings at birth are features that do not obviously harmonise with the idea of annual increases of two rings.' At the time, Parker \& Stott (1965) were unable to provide an alternate hypothesis.

While several of the previous studies that looked at band pairs in the basking shark noted the difference in band pair count along the vertebral column (Ridewood 1921, Parker \& Stott 1965, Desse \& Du Buit 1971), others have not found a difference along the column (Jägerskiöld 1915, Izawa \& Shibata 1993). The disparity between these studies is in the length and condition of the specimens examined. Izawa \& Shibata (1993) examined a $260 \mathrm{~cm}$ specimen which had 8 band pairs. In the present study we also examined a specimen (no. 36) of $260 \mathrm{~cm} \mathrm{TL}$, which had 6 to 7 band pairs. The difference in counts between these same-sized specimens could be due to individual variation or the fact that the specimen from the present study was emaciated and in very poor condition. If band pair deposition is related to girth and body support, the decreased number of band pairs in our specimen may be due to its being underweight and thus not having the girth to require support. This may also explain the low number of band pairs and lack of difference along the length of the vertebral column in the Jägerskiöld (1915) specimen. Photographs presented in that publication show a thin, underweight specimen. This specimen would be expected to show some band pair count variation along the vertebral column based on our observations along the column of a $550 \mathrm{~cm}$ specimen which had band pair counts ranging from 8 to 18 for small and large vertebrae, respectively. Jägerskiöld's (1915) specimen had fewer bands than would be expected on the largest vertebrae based on length (our $457 \mathrm{~cm}$ specimen had 12 band pairs and our $550 \mathrm{~cm}$ specimen had 18). The count is not in question as our Sample 25 is Jägerskiöld's (1915) sample and we obtained the same count (12). While the lower band pair count could be due to individual variation, combined with the lack of variation along the column, this suggests that this specimen is anomalous. Ridewood (1921) and Desse \& Du Buit (1971), examined specimens of various stages (an adult, a young individual and an individual of $15 \mathrm{~m} \mathrm{TL}$ ), and did find a difference in band pair count in vertebrae taken from along the vertebral column. Parker \& Stott (1965) noted Ridewood's (1921) findings of changes in counts along the column and though their specimens widely ranged in length (475 to $877 \mathrm{~cm}$ ), they sampled from 1 area along the column to maintain consistency. Since none of these previous authors examined whole columns from a range of specimen lengths, they did not take note of the ontogenetic changes in band pair number.
Vertebral growth zone deposition in the basking shark is similar to that of the angel shark Squatina californica (Natanson \& Cailliet 1990). The angel shark, the gummy shark Mustelus antarcticus and the school shark Galeorhinus galeus have all been found to have a change in band pair count along the vertebral column (Ridewood 1921, Natanson \& Cailliet 1990, Officer et al. 1996). In both the angel shark and the basking shark, the band pair counts along the vertebral column are similar in the young, and progressively become variable along the column so that in adults, counts are low in the cranial vertebrae, increase to a plateau at the anterior abdominal area and decrease toward the tail (Natanson \& Cailliet 1990; their Fig. 2). Additionally, Natanson \& Cailliet (1990) documented that angel sharks are born with $\sim 7$ band pairs. Parker \& Stott (1965) first suggested that basking sharks had 7 or possibly 8 band pairs at birth, which corresponds to results from the present study indicating an average of 8 pre-birth band pairs. Most elasmobranch age studies do not indicate if band pair counts along the vertebral column were examined; however, this is an important step in determining the usefulness of the vertebrae as an aging structure. Consistency in location of vertebral sampling is important not only for calculating the relationship between vertebral dimension and body length (Natanson et al. 2006, Piercy et al. 2006) but also for comparison of band pair count. Though many studies have shown that band pair counts are consistent along the vertebral column (Natanson et al. 2002, 2006, Joung et al. 2004, Kneebone 2005, Bishop et al. 2006, Piercy et al. 2006, B. Gervelis [NMFS] unpubl. data), the results of those studies that do show a difference highlight the need to examine band pair counts along the column of every species aged.

Angel sharks deposit band pairs relative to growth rather than time (Natanson \& Cailliet 1990) and the similarities in vertebral growth between the angel shark and the basking shark suggest that vertebral growth in basking shark might also be related to somatic growth; however, age validation for the basking shark has not been completed. The consistency of the growth bands suggests that they might be related to a structural component of the vertebral column and the increase in structural bands in the thickest part of the shark also suggests a strengthening component. Band pair deposition in the angel shark appears to be related to growth in girth and therefore to provide physical support for the growing vertebrae in the widest part of the animal (Natanson \& Cailliet 1990). Unfortunately, girth data were not available for most of the samples in the present study for comparison.

Counting band pairs in the basking shark is not difficult regardless of preparation method. There is a high 
level of repeatability of counts within each method. Results between methods, however, indicate that use of X-radiography overestimates band pair number in specimens with $>17$ band pairs. Most of the previous studies on the basking shark appear to use either sections or whole vertebrae, and thus band pair counts between studies are comparable if the vertebrae are taken from the same location of the vertebral column. Often this is not the case, which explains the discrepancy between Springer \& Gilbert's (1976) Sarasota basking shark 'age' (16) and Eastern Atlantic specimens of similar length (22). Springer \& Gilbert (1976) were comparing the counts from a pelvic vertebra to counts from a pre-caudal vertebra. A count difference of $>7$ band pairs could be obtained from these 2 areas of the vertebral column in a shark this length (based on counts from a similar length shark; Specimen 38; Table 2).

Overall, band pair counts from the present study seem to fit those reported in the literature, although there is count variation in specimens of similar lengths. This difference could be due to the unknown location of some of these vertebrae along the respective vertebral columns or to individual variation in somatic growth (Fig. 7b). Lein \& Aldrich (1982) presented a maximum and a minimum count for their samples. They noted the change in counts along the column and the maximum count came from the largest vertebra from a specimen (J. Lein pers. comm.). Additionally, they were counting on the face of fresh (unpreserved) unprepared vertebrae (J. Lein pers. comm.). Due to the similarity in location of these vertebrae to our 21 samples of known location, we can compare the counts between the studies and thus enhance the sample size.

Changes in band pair width led to Parker \& Stott's (1965) conclusion that 7 band pairs were deposited prior to birth. Because they assumed no difference in pre-gestational and post-gestational deposition, they estimated a 3.5 yr gestation. Current information on the pre-birth bands for the angel shark gives us more insight as to possibilities for the basking shark. The angel shark has 7 pre-birth band pairs yet has only a 10 mo gestation period. The 7 pre-birth bands are presumably what is needed mechanically to support the neonate at the birth length. The change in band spacing between pre- and postnatal basking shark vertebra noted by Parker \& Stott (1965) is possibly related to the change in growth rate between the rapidly growing embryo and the slower growing neonate. Our finding of 8 pre-birth bands corresponds to an average length at birth of $197 \mathrm{~cm}$ TL using the quadratic-modified and $301 \mathrm{~cm}$ TL using the linear-modified Dahl-Lea backcalculation equations. Currently, the birth length of this species is not well documented. Matthews (1950) suggested a birth length of 6 feet (183 cm TL) based on a lack of observations of smaller individuals. Springer \& Gilbert (1976) stated that no free-swimming young $<200 \mathrm{~cm}$ have been recorded; however, the smallest free-swimming specimen is $180 \mathrm{~cm}$ (Lein \& Fawcett 1986). Historically, Templeman (1963) reported on a $200 \mathrm{~cm}$ postnatal specimen from 1833. These appear to be the smallest reliably reported specimens on record. The few measured small free-swimming specimens are similar in length to those mentioned in the anecdotal reports and suggest a reasonable estimated birth length for Cetorhinus maximus of approximately 180 to $200 \mathrm{~cm}$, which is similar to our quadratic-modified Dahl-Lea estimate (197 cm TL). This suggests that the quadratic-estimated back-calculation is, both statistically and biologically, the preferred method for estimating age at previous length in this species.

The current evidence suggests that the basking shark may deposit band pairs relative to structural morphology rather than time. Regardless, it is evident that while the vertebrae from the basking shark grow proportionally to the body length and have distinct band pairs, the band pairs may not be formed relative to an increment of time, and thus the vertebrae from this species may not be useful for determining age. Ongoing studies into the validation of the band pairs should provide a more definitive picture of the vertebral deposition in this species.

Acknowledgements. The assistance of the following people is gratefully acknowledged: D. C. Bernvi, B. C. Delius, P. Deynat, G. Nilson, C. Stenberg and 2 anonymous persons who assisted in organizing X-radiography in a private hospital in Algiers. We thank B. Runsten and J. Fong for providing X-radiographs for this study. We thank S. F. J. Dudley for comments on an earlier draft of the manuscript. W. Ledwell and J. Lein provided invaluable information. K. Goldman contributed much needed back-calculation expertise. G. Cailliet and G. Skomal assisted by reviewing early versions of the manuscript and acting as sounding boards for us in this study.

\section{LITERATURE CITED}

Bigelow HB, Schroeder WC (1948) Fishes of the western North Atlantic. 1, Sharks. Mem Sears Found Mar Res 1:59-576

Bishop SDH, Francis MP, Duffy C, Montgomery JC (2006) Age, growth, maturity, longevity and natural mortality of the shortfin mako (Isurus oxyrinchus) in New Zealand waters. Mar Freshw Res 57:143-154

Bowker AH (1948) A test for symmetry in contingency tables. J Am Stat Assoc 43:572-574

Cadenat J, Blache J (1981) Requins de Mediterranée et d'Atlantique, plus particulièrement de la Côte Occidentale d'Afrique. Faune Trop ORSTOM 21:149-152

Cailliet GM, Goldman KJ (2004) Age determination and validation in chondrichthyan fishes. In: Carrier J, Musick JA, Heithaus MR (eds) Biology of sharks and their relatives. CRC Press, Boca Raton, FL, p 399-447

> Campana SE, Annand MC, McMillan JI (1995) Graphical and statistical methods for determining the consistency of age determinations. Trans Am Fish Soc 124:131-138 
Casey JG, Pratt HL Jr, Stillwell CE (1985) Age and growth of the sandbar shark (Carcharhinus plumbeus) from the western North Atlantic. Can J Fish Aquat Sci 42:963-975

Castro JI, Woodley CM, Brudek RL (1999) A preliminary evaluation of the status of shark species. FAO Fish Tech Pap 380:1-72

Chang WYB (1982) A statistical method for evaluating the reproducibility of age determination. Can J Fish Aquat Sci 39:1208-1210

Chen JTF (1963) A review of the sharks of Taiwan. Biol Bull Dep Biol Tunghai Univ (Ichthyol Ser 1) 19:1-102

Desse G, Du Buit MH (1971) Diagnostic des pièces rachidiennes des Téléostéens et des Chondrichthyens. II Chondrichthyens. Expansion Scientifique Française, Paris

Evans GT, Hoenig JM (1998) Testing and viewing symmetry in contingency tables, with application to readers of fish ages. Biometrics 54:620-629

Goldman KJ (2004) Age and growth of elasmobranch fishes. In: Musick JA, Bonfil R (eds) Elasmobranch fisheries management techniques. FAO Fish Tech Pap 6:97-132

Hasse JCF (1882) 1879-85 Das natuerliche System der Elasmobranchier auf Grundlage des Baues und der Entwicklung ihrer Wirbelsaeule. Eine morphologische und palaeontologische Studie. Gustav Fischer, Jena, Germany

Hoenig JM, Morgan MJ, Brown CA (1995) Analyzing differences between two age determination methods by tests of symmetry. Can J Fish Aquat Sci 52:364-368

Howes CA (1998) Basking sharks Cetorhinus maximus (Gunnerus) stranded on the Yorkshire coast. Naturalist 123: 101-102

Izawa K, Shibata T (1993) A young basking shark, Cetorhinus maximus, from Japan. Jpn J Ichthyol 40:237-245

Jägerskiöld LA (1915) On a basking shark - Cetorhinus maximus (Gunnerus) - found in Sweden. Göteborgs Kongl Vetensk Vitterh Samh Handl 16:3-13

Joung SJ, Liao YY, Chen CT (2004) Age and growth of the sandbar shark, Carcharhinus plumbeus, in northeastern Taiwan waters. Fish Res 70:83-96

Kneebone J (2005) Validated age and growth estimates for the tiger shark Galeocerdo cuvier, in the western North Atlantic. Ms thesis, University of New Hampshire, Durham

Lein J, Aldrich D (1982) The basking shark (Cetorhinus maximus) in Newfoundland. Department of Fisheries, Government of Newfoundland and Labrador, St. John's

Lein J, Fawcett L (1986) Distribution of basking sharks, Cetorhinus maximus, incidentally caught in inshore fishing gear in Newfoundland. Can Field Nat 100:246-252

Matthews LH (1950) Reproduction in the basking shark, Cetorhinus maximus (Gunner). Philos Trans R Soc Lond A 234:247-316

McNemar Q (1947) Note on the sampling error of the difference between correlated proportions or percentages. Psychometrika 12:153-157

Natanson LJ, Cailliet GM (1990) Vertebral growth zone deposition in Pacific angel sharks. Copeia 1990:1133-1145

Natanson LJ, Mello JJ, Campana SE (2002) Validated age and growth of the porbeagle shark (Lamna nasus) in the western North Atlantic Ocean. Fish Bull (Wash DC) 100: 266-278

Natanson LJ, Ardizzone D, Cailliet GM, Wintner S, Mollet H (2006) Validated age and growth estimates for the shortfin mako, Isurus oxyrinchus, in the North Atlantic Ocean. In: Goldman KJ, Carlson JK (eds) Proc Am Elasmobranch Soc 21st Mtg, July 2005, Tampa, FL. Environ Biol Fish 77: 367-383

Officer RA, Gason AS, Walker TI, Clement JG (1996) Sources of variation in counts of growth increments in vertebrae from gummy shark, Mustelus antarcticus, and school shark, Galeorhinus galeus: implications for age determination. Can J Fish Aquat Sci 53:1765-1777

Parker HW, Boeseman M (1954) The basking shark, Cetorhinus maximus, in winter. Proc Zool Soc Lond 124:185-194

Parker HW, Stott FC (1965) Age, size and vertebral calcification of the basking shark, Cetorhinus maximus (Gunnerus). Zool Meded 40:305-319

Pauly D (1978) A critique of some literature data on the growth, reproduction and mortality of the lamnid shark Cetorhinus maximus (Gunnerus). ICES CM 17:1-10

Pauly D (2002) Growth and mortality of the basking shark Cetorhinus maximus and their implications for management of whale sharks Rhincodon typus. In: Fowler SL, Reed TM, Dipper FA (eds) Elasmobranch biodiversity, conservation and management. IUCN, Gland, p 199-208

Piercy AN, Ford TS, Levy LM, Snelson FF Jr (2006) Analysis of variability in vertebral morphology and growth ring counts in two Carcharhinid sharks. Environ Biol Fish 77:401-406

Ridewood WG (1921) On the calcification of the vertebral centra in sharks and rays. Philos Trans $\mathrm{R}$ Soc Lond B 210:311-407

Schwartz FJ (2002) Basking sharks, Cetorhinus maximus, family Cetorhinidae, recorded in North Carolina waters 1901-2002. J NC Acad Sci 118:201-205

Serena F, Vacchi M, Notarbartolo di Sciara G (2000) Geographical distribution and biological information on the basking shark, Cetorhinus maximus in the Tyrrhenian and Ligurian seas. In: Séret B, Sire JY (eds) Proc Eur Elasmobranch Assoc 3rd Mtg, Boulogne-sur-Mer, France, May 1999. Société Française d'Ichtyologie and Institut de Recherche pour le Développement (IRD), Paris, p 47-56

Siccardi EM (1961) 'Cetorhinus' en el Atlantico Sur (Elasmobranchii: Cetorhinidae). Rev Mus Argent Cienc Nat Bernadino Rivadavia Inst Nac Investig Cienc Nat Zool 6: 61-101

Soldo A, Peharda M, Onofri V, Glavic N, Tutman P (1999) New record and some morphological data of the basking shark, Cetorhinus maximus (Gunnerus, 1765), in the eastern Adriatic. Ann Ser Hist Nat 9:229-232

Springer S, Gilbert PW (1976) The basking shark, Cetorhinus maximus, from Florida and California, with comments on its biology and systematics. Copeia 1976:47-54

Templeman W (1963) Distribution of sharks in the Canadian Atlantic (with special reference to Newfoundland waters). Bull Fish Res Board Can 140:1-77

Walker WF (1975) Vertebrate dissection, 5th edn. WB Saunders, Philadelphia

Wintner SP (2000) Preliminary study of vertebral growth rings in the whale shark, Rhincodon typus, from the east coast of South Africa. Environ Biol Fishes 59:441-451

Wood FG Jr (1957) Southern extension of the known range of the basking shark, Cetorhinus maximus (Gunnerus). Copeia 1957:153-154

Zuffa M, Soldo A, Storai T (2001) Preliminary observations on abnormal abundance of Cetorhinus maximus (Gunnerus, 1765) in the central and northern Adriatic Sea. Ann Ser Hist Nat 11:185-192

Submitted: July 26, 2007; Accepted: January 9, 2008

Proofs received from author(s): May 21, 2008 